\title{
DOSES DE NITROGÊNIO E POTÁSSIO EM FERTIRRIGAÇÃO EM MARACUJAZEIRO- AMARELO CONSORCIADO COM COQUEIRO-ANÃO VERDE, NA REGIÃO NORTE FLUMINENSE ${ }^{1}$
}

\author{
RAUL CASTRO CARRIELLO ROSA ${ }^{2}$, PEDRO HENRIQUE MONNERAT ${ }^{3}$, ANSELMO LÚCIO DOS SANTOS ${ }^{4}$, ANDRÉ \\ ASSIS PIRES ${ }^{5}$, LEANDRO GLAYDSON DA ROCHA PINHO ${ }^{6}$, AMANDA OLIVEIRA MARTINS ${ }^{7}$
}

RESUMO - Com o objetivo de avaliar os efeitos de doses de nitrogênio $(\mathrm{N})$ e potássio $(\mathrm{K})$ na água de irrigação, sobre a produtividade e os teores foliares de nutrientes minerais em maracujazeiro-amarelo consorciado com coqueiro-anão verde no Norte Fluminense, foi instalado um experimento em delineamento inteiramente casualizado, com 2 tratamentos (2 doses de adubação, em fertirrigação: 1) N=161 e K=215 kg ha-1 ano-1, e 2) N=322 e $\mathrm{K}=430 \mathrm{~kg} \mathrm{ha}^{-1}$ ano $^{-1}$ ) e 12 repetições, em um solo classificado como Neossolo Quartzarênico. As plantas foram irrigadas por microaspersão, com emissores com vazão de $60 \mathrm{~L} \mathrm{hora}^{-1}$, sendo um para cada pé de coco com quatro pés de maracujá, utilizando lâmina de $75 \%$ de Et ${ }_{0}$. A injeção do fertilizante foi feita por injetor do tipo Venturi. As unidades experimentais constaram de 5 plantas de coco e 20 de maracujá. Realizaram-se 5 amostragens foliares no maracujazeiro, com intervalos trimestrais. As amostras consistiram de 20 folhas recém-maduras, coletando-se a $5^{\text {a }}$ folha do ápice para a base do ramo. Determinaram-se os teores de $\mathrm{N}, \mathrm{P}, \mathrm{K}, \mathrm{Ca}, \mathrm{Mg}, \mathrm{S}, \mathrm{Cl}, \mathrm{Na}, \mathrm{Fe}, \mathrm{Zn}, \mathrm{Cu}, \mathrm{Mn}$ e $\mathrm{B}$. As doses de $\mathrm{N}$ e $\mathrm{K}$ não influenciaram na produtividade e no peso médio do fruto; apenas, os teores foliares de N, Ca e Zn, em algumas épocas de amostragem.

Termos para Indexação: Passiflora edulis Simsf. flavicarpa Deg., adubação, Neossolo Quartzarênico, avaliação nutricional, Cocos nucifera L.

\section{DOSES OF NITROGEN AND POTASSIUM IN FERTIRRIGATION ON YELLOW PASSION FRUIT PLANT INTERCROPED WITH GREEN DWARFISH COCONUT TREE IN THE NORTH OF THE STATE OF RIO DE JANEIRO}

\begin{abstract}
An experiment was undertaken to evaluate the effects of two doses of fertilizers in fertirrigation on yield and leaf mineral composition of yellow passion fruit plant cultivated in consortium with green dwarfish coconut tree grown in a Quartzarenic Neosoil in the north of the state of Rio de Janeiro. Fertilizer doses were: 1) $\mathrm{N}=161$ and $\mathrm{K}=215 \mathrm{~kg} \mathrm{ha}^{-1}$ year ${ }^{-1}$ and 2) $\mathrm{N}=322 \mathrm{and} \mathrm{K}^{2}=430 \mathrm{~kg} \mathrm{ha}^{-1}$ year ${ }^{-1}$. Treatments had 12 replicates in a

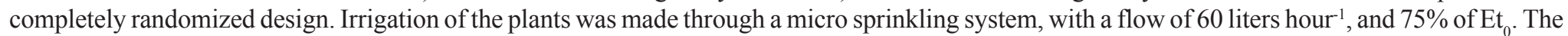
injection of the fertilizer was made through a Venturi type injector, coupled with a $1 \mathrm{hp}$ pump. The experimental units consisted of 5 coconut plants and 20 passion fruit plants. Five leaf samples were taken at three month intervals. Samples were composed of 20 recently mature leaves, colecting the 5th leaf from the apex of the branch. Leaf N, P, K, Ca, Mg, S, Cl, Na, Fe, Zn, Cu, Mn and B contents were determined. Doses of applied fertilizers didn't differ in terms of yield and fruit average weight. Nitrogen and potassium fertilization doses affected only $\mathrm{N}, \mathrm{Ca}$, and $\mathrm{Zn}$ leaf concentrations in a few sampling times.
\end{abstract}

Index terms: Passiflora edulis Sims f. flavicarpa Deg., fertilization, Quartzarenic Neosoil, mineral composition, Cocos nucifera L.

\section{INTRODUÇÃO}

O cultivo do maracujazeiro nas regiões norte e noroeste Fluminense é praticado principalmente por pequenos e médios produtores, com baixo nível tecnológico, sendo a produtividade média muito baixa, em torno de 8-12 tha ${ }^{-1}$. A utilização de adubações e irrigações em níveis inadequados tem sido responsável por produtividades tão baixas (Carvalho et al., 2001). Visando ao estabelecimento de recomendações de adubação com os nutrientes $\mathrm{N}$ e K, os exigidos em maiores quantidades pelo maracujazeiro-amarelo, e de lâminas de irrigação adequadas para as regiões norte e noroeste Fluminense, Carvalho (1998) obteve as maiores produtividades, acima de $40 \mathrm{t} \mathrm{ha}^{-1}$, com as doses de $290 \mathrm{~g}$ de N e $434 \mathrm{~g}_{\text {de }} \mathrm{K} \mathrm{ha}^{-1} \mathrm{ano}^{-1}$ e lâmina de $75 \%$ da $\mathrm{ET}_{0}$, em Argissolo Amarelo distrófico. Entretanto, Borges et al. (2002), avaliando os efeitos de doses de N, P e K em Cruz das Almas-BA, em Latossolo Amarelo franco-argilo-arenoso, com $2 \mathrm{mg} \mathrm{kg}^{-1}$ de $\mathrm{P}$ e $78 \mathrm{mg}$ $\mathrm{kg}^{-1}$ de $\mathrm{K}$, não obtiveram efeitos sobre a produtividade nem sobre os teores de $\mathrm{N}$ e $\mathrm{P}$ nas folhas. As doses de $\mathrm{K}$ aumentaram, ligeiramente, os teores de $\mathrm{K}$ nas folhas. A produtividade máxima obtida foi de 22,1 tha${ }^{1}$, em dois anos de cultivo, com as doses de $244 \mathrm{~kg}$ de N, 31,4 kg de P e $236,6 \mathrm{~kg}_{\text {de }} \mathrm{K} \mathrm{ha}^{-1} \mathrm{ano}^{-1}$. Há necessidade, portanto, de que existam recomendações de adubação adequadas para a região ou local em que a cultura será estabelecida.
A aplicação de fertilizantes via água de irrigação, fertirrigação, é uma alternativa bastante promissora à adubação convencional. Ela tem sido utilizada com maiores vantagens em solos de textura arenosa do que em solos de textura argilosa, principalmente com o uso de adubos nitrogenados (Hagin \& Tucker, 1982; Vitti \& Boaretto, 1994). Estes autores citam, ainda, as vantagens do fracionamento da aplicação de fertilizantes via água de irrigação, uma vez que o fornecimento parcelado de minerais atende às diferentes etapas de desenvolvimento das plantas e permite maior eficiência de aproveitamento e economia de fertilizantes.

A análise foliar é uma ferramenta importante para avaliar o estado nutricional das plantas para corrigir ou prevenir eventuais deficiências minerais. Em maracujazeiro-amarelo, ocorrem variações nos teores foliares de nutrientes devido à fase fenológica da planta e à época do ano, sugerindo a utilização de faixas adequadas de nutrientes no tecido foliar como uma ferramenta para a avaliação do estado nutricional das plantas (Menzel et al., 1993). Carvalho et al. (2001) observaram as seguintes faixas em população de alta produtividade (41,3 t ha-1 $)$, na região norte Fluminense: em $\mathrm{g} \mathrm{kg}^{-1}, 40,8$ a 58,1 de N; 2,58 a 3,85 de P; 23,2 a 38 de K; 6, 13 a 14,4 de Ca; 2,23 a 4,28 de Mg; 3,20 a 4,64 de S; 13,1 a 32,4 de Cle, em mg kg-1 , 18,8 a 48,9 de B; 3,97 a 234 de Cu; 82 a 246 de Fe; 44,4 a 94,5 de Mn e 21,1 a 36,5 de Zn. As faixas consideradas adequadas para Malavolta et al. (1997) são: em g kg-1 , 40,0 a 50 de N; 4 a 5 de P; 35 a 45 de $\mathrm{K} ; 15$ a 20 de Ca; 3 a 4 de Mg; 3 a 4 de S; em mg kg\footnotetext{
carrielo@uenf.br.

3 Professor Titular, UENF/CCTA/LFIT. monnerat@uenf.br.

${ }^{4}$ Dr. Produção Vegetal, Bolsista FENORTE/UENF/CCTA/LFIT. alsantos@uenf.br.

${ }^{5}$ Ms. Fitotecnia, Bolsista FENORTE/UENF/CCTA/LFIT.

${ }^{6}$ Mestrando em Produção Vegetal, UENF/CCTA/LFIT.

Estudante de Agronomia, UENF/CCTA/LFIT.
}

${ }^{1}$ (Trabalho 169/2004). Recebido: 20/12/2004. Aceito para publicação: 23/02/2006. Projeto Financiado pela FAPERJ, Processo E-26/152.352/2002.

2 Doutorando em Produção Vegetal, UENF/CCTA/LFIT. Av. Alberto Lamego, 2000, Campos dos Goytacazes-RJ - CEP: $28013-600$. Fone: (22) 2726 1425. 
TABELA 1 - Resultado da análise química do solo da área experimental. São Francisco do Itabapoana-RJ. 2003.

\begin{tabular}{cccccccccc}
\hline Profundidade & C. E. & $\mathrm{pH}\left(\mathrm{H}_{2} \mathrm{O}\right)$ & $\mathrm{M} . \mathrm{O}$. & $\mathrm{P}$ & $\mathrm{K}$ & $\mathrm{Na}$ & $\mathrm{Al}$ & $\mathrm{Ca}$ & $\mathrm{Mg}$ \\
\hline$(\mathrm{cm})$ & $\mathrm{mS} \mathrm{cm}^{-1}$ & & $\mathrm{~g} \mathrm{dm}^{-3}$ & $\mathrm{mg} \mathrm{dm}^{-3}$ & & & $\mathrm{mmol}_{\mathrm{c}} \mathrm{dm}^{-3}$ & & \\
$2-20$ & 2,2 & 5,2 & 16,3 & 8,2 & 0,9 & 5,6 & 1,1 & 10,4 & 7,2 \\
$20-40$ & 1,5 & 5,2 & 11,4 & 4,2 & 0,7 & 3,7 & 1,0 & 8,8 & 4,2 \\
$40-60$ & 1,5 & 5,1 & 7,0 & 3,0 & 0,5 & 2,6 & 1,0 & 5,6 & 2,4 \\
\hline
\end{tabular}

C. E.: Condutividade elétrica; M.O.: Matéria orgânica

1, 40 a 50 de B; 10 a 20 de Cu; 120 a 200 de Fe; 400 a 600 de Mn e 25 a 40 de Zn.

A alternativa do consórcio é utilizada como uma forma de aumentar a eficiência do uso do solo, além de permitir uma diluição dos custos iniciais na implantação do coqueiro, sendo esta cultura, a principal, de maneira que a cultura em consórcio seja estabelecida nos primeiros quatro anos após a implantação do coqueiro, pois, neste período, ocorre crescimento mais lento, além de menor expansão do sistema radicular. A escolha da cultura é em função do clima da região, do retorno econômico e do baixo potencial competitivo, estando o maracujazeiro dentro destes requisitos para a região (Sobral, 1998).

O objetivo deste trabalho foi avaliar os efeitos de duas doses de nitrogênio e potássio, aplicadas na água de irrigação, na produtividade e peso médio de frutos, e nos teores foliares de nutrientes minerais em maracujazeiro-amarelo cultivado em consórcio com coqueiro-anão verde no norte do Estado do Rio de Janeiro.

\section{MATERIALE MÉTODOS}

Na Fazenda Batelão, situada no município de São Francisco de Itabapoana - RJ, coordenadas $21^{\circ} 18^{\prime} 35^{\prime \prime} \mathrm{W}$ e $40^{\circ} 59^{\prime \prime} 39^{\prime \prime} \mathrm{S}$, em um solo (Tabelas 1 e 2) classificado como Neossolo Quartzarênico, conduziuse um experimento em um coqueiral, com cinco meses de idade, consorciado com maracujazeiro-amarelo nas entrelinhas, irrigados por microaspersão, utilizando emissores com vazão de $60 \mathrm{~L}^{\text {hora }}{ }^{-1}$. O delineamento experimental foi o inteiramente casualizado, com dois tratamentos e 12 repetições. As unidades experimentais foram formadas por cinco coqueiros e 20 maracujazeiros. Os tratamentos consistiram em duas doses de $\mathrm{N}$ e $\mathrm{K}$ aplicadas via fertirrigação. As doses foram definidas de acordo com Carvalho (1998), para maracujazeiro, somadas às do coqueiro, estabelecida por Sobral (1998). As doses de adubação aplicadas por fertirrigação foram: dose $1=50 \%$ da adubação recomendada por Carvalho (1998), para o maracujazeiro $+50 \%$ da dose estabelecida por Sobral (1998), para o coqueiro, resultando em $161 \mathrm{~kg}$ $\mathrm{ha}^{-1} \mathrm{ano}^{-1}$ de N e $215 \mathrm{~kg} \mathrm{ha}^{-1}$ ano $^{-1}$ de $\mathrm{K}$; a dose 2 foi equivalente a $100 \%$ da dose recomendada (322 e $430 \mathrm{~kg} \mathrm{ha}^{-1} \mathrm{ano}^{-1}$ ), respectivamente para $\mathrm{N}$ e K. Realizou-se uma adubação com $2 \mathrm{~kg} \mathrm{ha}^{-1}$ de ácido bórico na água de irrigação. As adubações, via fertirrigação, foram parceladas em seis vezes por semana. A água usada na irrigação foi classificada como
C3S2, conforme Bernardo (1995), apresentando alta condutividade e média concentração de sódio (Tabela 3 ). $\mathrm{O}$ fósforo, na forma de superfosfato simples, recomendado para o coqueiro, foi aplicado em cobertura, trimestralmente.

O maracujazeiro foi plantado (duas mudas espaçadas de $2 \mathrm{~m}$ ) em duas linhas paralelas à linha do coqueiral, sendo uma de cada lado do coqueiro, totalizando quatro maracujazeiros para cada coqueiro. Os maracujazeiros foram conduzidos no sistema de espaldeira vertical, com um fio de arame a 1,8 $\mathrm{m}$ de altura em relação ao nível do solo, estando afastados 1,8 metro do tronco do coqueiro, resultando em um espaçamento de 3,6 m entre linhas para a cultura do maracujazeiro. A cultura do coqueiro foi plantada em quadrado, com espaçamento de $7 \mathrm{~m}$ entre plantas. Desta forma, estabeleceu-se uma população de 204 coqueiros e 816 maracujazeiros por hectare. As mudas de coqueiro foram plantadas em setembro de 1999 e receberam apenas esterco de curral como adubação de plantio. O maracujazeiro foi plantado em fevereiro de 2000, e a adubação de plantio constou de $300 \mathrm{~g}$ de calcário dolomítico no fundo da cova, $12 \mathrm{~g}$ de N, 6, $1 \mathrm{~g}$ de $\mathrm{P}, 6,6 \mathrm{~g}$ de $\mathrm{K}$ e $50 \mathrm{~g}$ do formulado com micronutrientes FTE-BR12 incorporado na terra de enchimento da cova.

Irrigaram-se as plantas por microaspersão, utilizando emissor com vazão de $60 \mathrm{~L} \mathrm{~h}^{-1}$, sendo um emissor para cada coqueiro com quatro maracujazeiros, com uma lâmina de $75 \%$ de $\mathrm{Et}_{0}$, pois foi a que apresentou melhores resultados para o maracujazeiro na região norte Fluminense, segundo Carvalho (1998). A injeção dos fertilizantes foi feita através de injetor do tipo Venturi, acoplado a uma bomba injetora de $1 \mathrm{CV}$. Os fertilizantes utilizados foram uréia $\left(450 \mathrm{~g} \mathrm{~kg}^{-1} \mathrm{de} \mathrm{N}\right)$, como fonte de $\mathrm{N}$, e cloreto de potássio branco (498 $\mathrm{g} \mathrm{kg}^{-1}$ de $\mathrm{K}$ ), como fonte de $\mathrm{K}$. Os fertilizantes foram injetados na linha principal do cabeçal de controle, antes do sistema de filtragem.

Efetuaram-se polinizações manuais nos principais picos de florada (1ㅇ-09 a 27-10-2000; 05-01 a 09-02-2001; 18-02 a 16-03-2001 e 0804 a 04-04-2001) e pulverizações preventivas com mancozeb e oxicloreto de cobre, para controle de doenças.

No período de condução do experimento, foram avaliados a composição mineral, os componentes da produção e os da qualidade dos frutos para a cultura do maracujá. A composição mineral das plantas de maracujá foi avaliada em amostras foliares coletadas trimestralmente. Foram coletadas, para análise, folhas recém-maduras e que continham

TABELA 2 - Análise granulométrica, umidade e densidade do solo da área experimental. São Francisco do Itabapoana-RJ. 2003.

\begin{tabular}{|c|c|c|c|c|c|c|c|c|c|}
\hline Profundidade & $\mathrm{AG}$ & $\mathrm{AM}$ & $\mathrm{AF}$ & AT & Silte & Argila & \multicolumn{2}{|c|}{ Umidade - \% } & Dap \\
\hline & ---- & ----- & 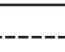 & & & & $1 / 3$ bar & $15 \mathrm{bar}$ & $\mathrm{g} \mathrm{dm}^{-3}$ \\
\hline $0-20$ & 340 & 130 & 490 & 970 & 0 & 30 & 4,5 & 1,4 & 1,49 \\
\hline $20-40$ & 330 & 130 & 520 & 970 & 0 & 30 & 5,3 & 0,9 & 1,55 \\
\hline $40-60$ & 330 & 150 & 510 & 980 & 0 & 20 & 3,9 & 0,5 & 1,59 \\
\hline
\end{tabular}

Classificação textural: Areia

Areia grossa (AG), Areia média (AM), Areia fina (AF), Areia total (AT), densidade aparente (Dap).

TABELA 3 - Resultado da análise química da água utilizada na fertirrigação. São Francisco do Itabapoana-RJ. 2003.

\begin{tabular}{|c|c|c|c|c|c|c|c|c|c|c|c|c|c|c|}
\hline $\mathrm{pH}$ & C. E. ${ }^{1}$ & $\mathrm{Na}$ & $\mathrm{K}$ & $\mathrm{Ca}$ & $\mathrm{Mg}$ & $\mathrm{CO}_{3}^{-}$ & $\mathrm{HCO}_{3}^{-}$ & $\mathrm{SO}_{4}^{-}$ & B & $\mathrm{Fe}$ & $\mathrm{Cu}$ & $\mathrm{Zn}$ & Mn & $\mathrm{Cl}$ \\
\hline & $\mathrm{mScm}^{-1}$ & ------ & $-\mathrm{mr}$ & $\mathrm{l}_{\mathrm{c}} \mathrm{dm}$ & -------- & -------- & ----- & ----. & ---- 1 & $\mathrm{~L}^{-1}$ & ------ & ---- & ------ & ------ \\
\hline 5,5 & 1,55 & 7,14 & 0,3 & 0,64 & 2,59 & 0 & 8 & 10,8 & 0,35 & 1,1 & 0,02 & 0,01 & 0,05 & 450 \\
\hline
\end{tabular}

C. E.: Condutividade elétrica 
TABELA 4 - Teores de N, Ca e Zn em folhas de maracujazeiro-amarelo consorciado com coqueiro-anão verde em função de doses de adubação e épocas de amostragem. São Francisco do Itabapoana-RJ. 2003.

\begin{tabular}{|c|c|c|c|c|c|c|c|c|c|c|c|c|}
\hline \multirow[t]{2}{*}{ Coleta } & \multicolumn{4}{|c|}{$\mathrm{N}\left(\mathrm{g} \mathrm{kg}^{-1}\right)$} & \multicolumn{4}{|c|}{$\mathrm{Ca}\left(\mathrm{g} \mathrm{kg}^{-1}\right)$} & \multicolumn{4}{|c|}{$\mathrm{Zn}\left(\mathrm{mg} \mathrm{kg}^{-1}\right)$} \\
\hline & $50^{\circ}$ & & $100 \%$ & & $50 \%$ & & $100 \%$ & & $50 \%$ & & $100 \%$ & \\
\hline $1^{\mathrm{a}} \mathrm{jul} / 00$ & $52,4 \mathrm{a}$ & $\mathrm{B}$ & $55,9 a$ & $\mathrm{~A}$ & $10,0 \mathrm{~b}$ & A & $7,7 \mathrm{c}$ & B & $33,3 \mathrm{a}$ & $\mathrm{B}$ & $41,9 a$ & A \\
\hline $2^{\mathrm{a}}$ out $/ 00$ & $48,4 \mathrm{~b}$ & B & $52,1 \mathrm{~b}$ & A & $11,8 \mathrm{ab}$ & A & $13,1 \mathrm{ab}$ & A & $28,4 \mathrm{a}$ & A & $31,3 \mathrm{bc}$ & A \\
\hline $3^{\mathrm{a}} \mathrm{fev} / 01$ & $43,6 \mathrm{c}$ & A & $42,4 \mathrm{c}$ & A & $13,0 \mathrm{a}$ & A & $13,7 \mathrm{a}$ & A & $29,1 \mathrm{a}$ & B & $35,0 \mathrm{ab}$ & A \\
\hline $4^{\mathrm{a}}$ jun/01 & $52,0 \mathrm{a}$ & A & $52,8 \mathrm{ab}$ & A & $10,4 b$ & A & $11,9 \mathrm{ab}$ & $\mathrm{A}$ & $28,6 \mathrm{a}$ & A & $26,4 \mathrm{c}$ & A \\
\hline $5^{\mathrm{a}}$ out $/ 01$ & $44,2 \mathrm{c}$ & A & $44,3 \mathrm{c}$ & A & $9,9 \mathrm{~b}$ & A & $11,1 \mathrm{~b}$ & A & $31,2 \mathrm{a}$ & A & $29,8 \mathrm{bc}$ & A \\
\hline
\end{tabular}

Médias seguidas de mesma letra minúscula na coluna e maiúscula na linha não diferem, pelo teste de Tukey, a 5\% de probabilidade.

nas suas axilas um botão floral bem próximo da antese, sendo, normalmente, a $4^{\mathrm{a}}$ ou $5^{\mathrm{a}}$ folha a partir do ápice do ramo. Foram coletadas 20 folhas por parcela, uma folha por planta. Após a coleta, as folhas foram acondicionadas em sacos de papel e secas em estufa com circulação forçada de ar à temperatura de $70^{\circ} \mathrm{C}$, durante 48 horas. Após a secagem, o material foi triturado em moinho (tipo Wiley) com peneira de 20 mesh e armazenado em frascos hermeticamente fechados.

Os nutrientes N, P, K, Ca, Mg, S, Cl, Na, Fe, Zn, Cu, Mn e B foram analisados de acordo com metodologias descritas por Malavolta et al. (1997), com modificações propostas por Monnerat S/D. O N foi determinado pelo método de Nessler, após submeter o material vegetal à oxidação pela digestão sulfúrica $\left(\mathrm{H}_{2} \mathrm{SO}_{4} \mathrm{e}_{2} \mathrm{O}_{2}\right)$. Para o $\mathrm{NO}_{3}$ - foi utilizado o método do ácido salicílico (Cataldo et al., 1975), com extração em banho-maria a $45^{\circ} \mathrm{C}$, por 1 hora. $\mathrm{O}$ mesmo extrato submetido ao banhomaria foi utilizado para a determinação do $\mathrm{Cl}$, dosado por titulação com $\mathrm{AgNO}_{3}$. Os teores dos nutrientes foram comparados com as faixas propostas por Carvalho et al. (2001) por terem sido obtidas na região norte Fluminense, onde o presente trabalho foi realizado.

Os efeitos dos tratamentos sobre a produtividade e peso médio dos frutos foram avaliados mediante pesagem e contagem dos frutos colhidos da área útil de cada parcela pelo menos duas vezes por semana, no período de novembro/2000 a novembro/2001. Os dados foram submetidos à análise de variância, e as médias, comparadas pelo teste de Tukey, a 5\%.

\section{RESULTADOS E DISCUSSÃO}

O peso médio de frutos e a produtividade (Figuras 1A e 1B) não diferiram entre as doses de adubação, indicando, portanto, que a dose menor seria a mais recomendada. Essa igualdade entre as doses pode ser atribuída à maior eficiência da fertirrigação, quando comparada com a adubação sólida tradicional, pois, além de o adubo ser aplicado solúvel em água, existe o fracionamento da adubação, ou seja, pouca quantidade aplicada em alta freqüência ( 6 vezes por semana), o que resulta em menor possibilidade de perdas, tornando todo o sistema de fertilização mais eficiente.

Apesar de o solo da área experimental ser classificado como Neossolo Quartzarênico (Tabela 2), com baixa fertilidade natural (Tabela 1) e baixa capacidade de retenção de umidade, e de a água utilizada na irrigação ter alta salinidade e média concentração de sódio (C3S2), as produtividades obtidas foram satisfatórias, de $24,5 \mathrm{tha}^{-1}$, em média. É oportuno salientar que essa produtividade foi obtida em uma cultura consorciada com coqueiro-anão, com população de 816 plantas ha-1. Portanto, o manejo da irrigação, com turno de rega diário, empregando água com elevado teor de cloreto e alta condutividade elétrica, mostrouse viável para a cultura do maracujazeiro nesta classe de solo. O peso médio dos frutos, em ambas as doses de $\mathrm{N}$ e $\mathrm{K}$, foi superior a $160 \mathrm{~g}$ (Figura 1A), classificando-se como Extra AA.

Houve interação entre doses de fertilizantes e épocas de amostragem foliar apenas para os teores foliares de N, Ca e Zn (Tabela 4), mas os teores mantiveram-se dentro da faixa relatada por Carvalho et al. (2001).

Os maiores teores foliares de $\mathrm{N}$ foram encontrados na dose 2, tanto na $1^{\text {a }}$ quanto na $2^{\text {a }}$ coleta (Tabela 4 ). É importante mencionar que houve, neste período, vigorosa floração e intensa frutificação, o que, provavelmente, ocasionou a diminuição nos teores foliares de $\mathrm{N}$ na segunda coleta. As diferenças encontradas entre as doses sobre o teor de $\mathrm{N}$ podem ser explicadas em função de um possível "consumo de luxo" na dose 2 , pois, no período de floração, conseqüentemente, de maior exigência, as plantas da dose 2 mantiveram o teor foliar acima de $50 \mathrm{~g} \mathrm{~kg}^{-1}$, ao contrário das plantas da dose 1 , onde os teores caíram para valores abaixo de $50 \mathrm{~g} \mathrm{~kg}^{-1}$ (Tabela 4). Entretanto, os valores encontrados para produção foram similares (Figura 1), indicando maior eficiência de aproveitamento do adubo na dose 1.

Em relação às épocas, os maiores teores de $\mathrm{N}$ foram verificados na $1^{\mathrm{a}}$ e na $4^{\mathrm{a}}$ coletas, independentemente da dose (Tabela 4). Os menores teores desse nutriente foram obtidos, para ambas as doses, em fevereiro/ 2001 e outubro/2001, final da primeira e da segunda safras, indicando translocação do $\mathrm{N}$ das folhas para os frutos. Essa variação em função da época de coleta também foi observada na Austrália por Menzel et al. (1993) e, em Campos dos Goytacazes, por Carvalho et al. (2001), ambos em condições de campo.

Os maiores teores foliares de Ca (Tabela 4) foram encontrados na terceira coleta (fevereiro/2001), ocasião de final da primeira safra. Nesta fase, o desenvolvimento de novos brotos foi menor, pois a planta estava em plena frutificação, que é um dreno fraco para cálcio; desta forma, o cálcio absorvido pelas raízes acumulou-se nas folhas, fato observado também por Carvalho et al. (2001).
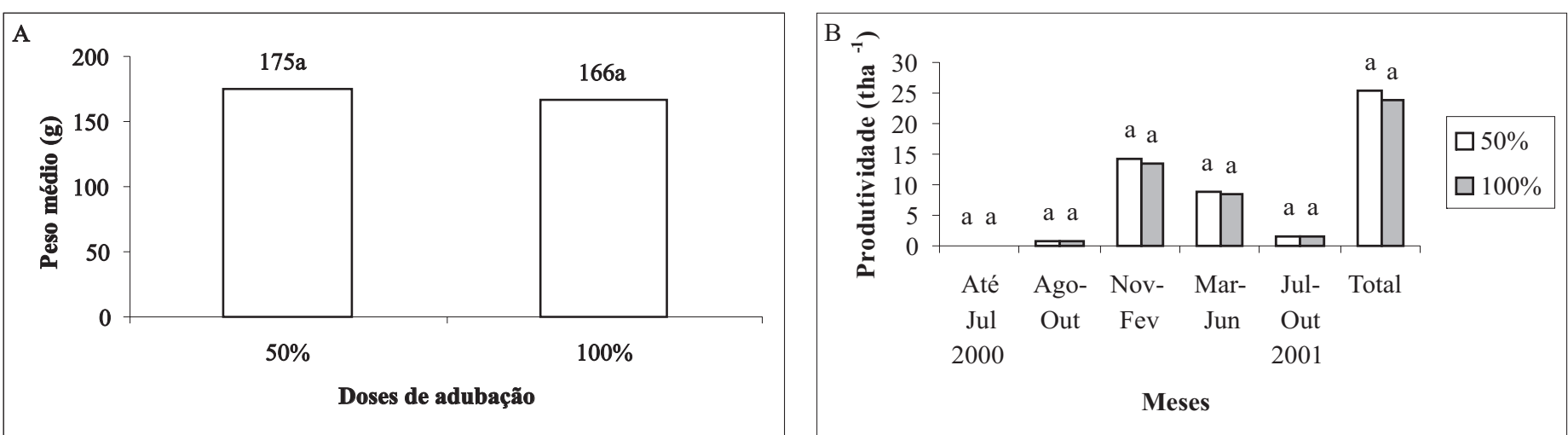

FIGURA 1 - Peso médio de frutos (A) e produtividade (B) do maracujazeiro-amarelo consorciado com coqueiro-anão verde em função de doses de adubação (50\% e 100\% da recomendação). São Francisco do Itabapoana-RJ. 2003. 
TABELA 5 - Teores de nutrientes em folhas de maracujazeiro-amarelo consorciado com coqueiro-anão verde em função de épocas de amostragem foliar. São Francisco do Itabapoana-RJ. 2003.

\begin{tabular}{|c|c|c|c|c|c|c|c|c|c|c|}
\hline Coleta & $\mathrm{P}$ & $\mathrm{K}$ & $\mathrm{Mg}$ & $\mathrm{S}$ & $\mathrm{Cl}$ & $\mathrm{Na}$ & $\mathrm{B}$ & $\mathrm{Cu}$ & $\mathrm{Fe}$ & $\mathrm{Mn}$ \\
\hline & \multicolumn{6}{|c|}{ 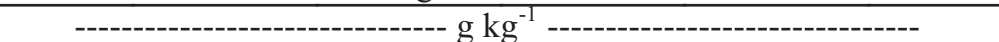 } & \multicolumn{4}{|c|}{----------------- $\mathrm{mg} \mathrm{kg}^{-1}$----------------- } \\
\hline $1^{\mathrm{a}} \mathrm{jul} / 00$ & $3,5 \mathrm{a}$ & $27,8 b$ & $2,5 \mathrm{~d}$ & $3,0 \mathrm{c}$ & $14,1 \mathrm{c}$ & $5,3 \mathrm{a}$ & $53,2 \mathrm{a}$ & $2,3 \mathrm{c}$ & $143 \mathrm{a}$ & $86 b$ \\
\hline $2^{\mathrm{a}}$ out $/ 00$ & $3,0 \mathrm{~b}$ & $25,1 b$ & $2,9 c$ & $3,7 b$ & $16,5 \mathrm{c}$ & $3,4 b$ & $34,3 \mathrm{c}$ & $17,4 \mathrm{a}$ & $103 \mathrm{abc}$ & $86 b$ \\
\hline $3^{\mathrm{a}} \mathrm{fev} / 01$ & $3,0 \mathrm{~b}$ & $26,7 b$ & $3,9 \mathrm{a}$ & $4,1 \mathrm{a}$ & $26,5 \mathrm{ab}$ & $4,2 b$ & $51,8 \mathrm{a}$ & $4,5 \mathrm{bc}$ & $71 \mathrm{c}$ & $86 b$ \\
\hline $4^{\mathrm{a}}$ jun/01 & $3,5 \mathrm{a}$ & $31,1 \mathrm{a}$ & $4,2 \mathrm{a}$ & $4,3 a$ & $24,5 b$ & $4,6 b$ & $50,5 \mathrm{a}$ & $6,3 \mathrm{~b}$ & $128 \mathrm{ab}$ & $130 a$ \\
\hline $5^{\mathrm{a}}$ out $/ 01$ & $2,8 \mathrm{~b}$ & $33,1 \mathrm{a}$ & $3,4 b$ & $3,5 \mathrm{~b}$ & $28,6 a$ & $6,1 \mathrm{a}$ & $42,6 b$ & $4,3 \mathrm{bc}$ & $89 b c$ & $66 \mathrm{~b}$ \\
\hline
\end{tabular}

Médias seguidas pela mesma letra na coluna não diferem, pelo teste de Tukey, a $5 \%$ de probabilidade.

Houve diferenças nos teores de $\mathrm{Zn}$ entre as doses nas coletas de julho/2000 e de fevereiro/2001, apresentando maiores valores na dose 2 (Tabela 4). Provavelmente, esse aumento pode ter sido ocasionado pela maior acidificação proveniente do uso de uréia como fonte de $\mathrm{N}$, ou a maior dose de $\mathrm{N}$ proporcionou maior decomposição da matéria orgânica e, conseqüentemente, maior liberação de Zn. Mesmo assim, os teores foliares de $\mathrm{Zn}$ (Tabela 4), em ambas as doses, mantiveram-se, geralmente, dentro da faixa considerada adequada por Carvalho et al. (2001).

Os teores foliares de P (Tabela 5) apresentaram-se dentro da faixa considerada adequada por Carvalho et al. (2001), em todas as épocas de coleta, sendo observado um acúmulo de $\mathrm{P}$ nas coletas realizadas em julho/2000 e junho/2001, pois, nesta época, observou-se menor crescimento vegetativo das plantas.

Para os teores foliares de K, foi observada baixa flutuação nas três primeiras épocas de coleta (Tabela 5), sendo que, nas duas últimas coletas (junho/2001 e outubro/2001), foram encontrados os maiores valores. Nesta fase, a cultura encontrava-se no final do ciclo, ocasião de pouca produção e diminuição na velocidade de crescimento. É importante mencionar que, mesmo em um solo classificado como Neossolo Quartzarênico, que apresenta baixo teor de K (Tabela 1), a fertirrigação foi eficiente, já que os teores foliares encontrados estavam dentro da faixa adequada (Carvalho et al., 2001) em todas as épocas de coleta, indicando que o fracionamento da adubação via fertirrigação supriu plenamente a necessidade de $\mathrm{K}$ da cultura em todas as épocas.

Os teores foliares de $\mathrm{Mg}$ (Tabela 5) apresentaram-se, em todas as coletas, dentro da faixa considerada adequada por Carvalho et al. (2001), sendo observadas diferenças entre as épocas de coleta, com flutuações semelhantes àquelas observadas para $\mathrm{Ca}$, ou seja, maiores valores em períodos de enchimento dos frutos, ocasião que coincide com a diminuição do crescimento vegetativo.

Os teores foliares de $\mathrm{S}, \mathrm{Cl}$ e $\mathrm{Na}$ (Tabela 5), em todas as coletas, encontraram-se adequados segundo as faixas propostas por Carvalho et al. (2001), sendo importante mencionar os altos valores de $\mathrm{Cl}$ e $\mathrm{Na}$ encontrados na água de irrigação (Tabela 3), que contribuíram para manter os teores destes elementos sempre altos.

$\mathrm{O}$ teor foliar de $\mathrm{Cu}$ na primeira coleta (Tabela 5) apresentou-se abaixo da faixa considerada adequada (Carvalho et al., 2001). Nesta época, as plantas não tinham recebido nenhuma pulverização preventiva com oxicloreto de cobre. A partir da segunda coleta, inclusive, pode ser observado aumento nos teores de $\mathrm{Cu}$ devido às pulverizações realizadas, passando para valores adequados, segundo Carvalho et al. (2001).

\section{CONCLUSÕES}

1. Não houve diferença na produtividade e no peso médio de frutos entre as doses de adubação nitrogenada e potássica, indicando melhor aproveitamento do adubo aplicado na menor dose.

2. Os teores dos nutrientes na matéria seca foliar variaram entre as diferentes épocas do ano, mas apenas os de N, Ca e $\mathrm{Zn}$ variaram com as doses de adubação, em algumas épocas.

\section{REFERÊNCIAS}

BERNARDO, S. Manual de irrigação. 6. ed. Viçosa: UFV, Imprensa Universitária, 1995. 657p.

BORGES, A.L.; CALDAS, R.C.; LIMA, A.A.; ALMEIDA, I.R. de. Efeito de doses de NPK sobre os teores de nutrientes nas folhas e no solo e na produtividade do maracujazeiro-amarelo. Revista Brasileira de Fruticultura, Jaboticabal, v.24, n.1, p.208-213, 2002.

CATALDO, D. A.; HAROON, M.; SCHRADER, L. E.; YOUNGS, V. L. Rapid colorimetric determination of nitrate in plant tissue by nitration of salicylic acid. Communication in Soil Science and Plant Analysis, Monticelli, v.6, n. 1: p.71-80, 1975.

CARVALHO, A.J.R.C. de. Composição mineral e produtividade do maracujazeiro-amarelo em resposta a adubações nitrogenada $e$ potássica sob lâminas de irrigação. 1998. 109f. (Tese de Doutorado em Produção Vegetal) -Universidade Estadual do Norte Fluminense Darcy Ribeiro, Campos dos Goytacazes, 1998.

CARVAlHO, A. J. C. de; MARTINS, D. P.; MONNERAT, P. H.; BERNARDO, S.; SILVA, J. A. Teores de nutrientes foliares no maracujazeiro-amarelo associados à estação fenológica, adubação potássica e lâminas de irrigação. Revista Brasileira de Fruticultura, Cruz das Almas, v.23, n.2, p.403-408, 2001.

HAGIN, J.; TUCKER, B. Fertilization of dryland and irrigated soils. Berlin: Springer-Verlag, 1982.190p.

MALAVOLTA, E.; VITTI, G. C.; OLIVEIRA, S. A. Avaliação do estado nutricional das plantas. 2. ed. Piracicaba: POTAFOS, 1997.316p.

MENZEL, C.M.; HAYDON, G.E.; DOOGAN, V.J.; SIMPSON, D.R. New standart leaf nutrient concentrations for passion fruit based on seasonal phenology and leaf composition. Journal of Horticultural Science, Ashford, v.68, p.215-230, 1993.

SOBRAL, F. L. Nutrição e adubação do coqueiro. In: FERREIRA, J. M. S.; WARWICK, D. R. N.; SIQUEIRA, L. A. (Ed.). A cultura do coqueiro no Brasil. Aracaju: Embrapa-SPI, 1998. p.129-157..

VITTI, G. C. ; BOARETTO, A. E. Fertilizantes fluidos. Piracicaba: POTAFOS, 1994.343p. 